\title{
Male prison transfers to the Central Mental Hospital, a special hospital (1983-1988)
}

*Art O'Connor MB, MRCPsych, Consultant Forensic Psychiatrist, and Helen O'Neill, MB, MRCPsych, Registrar, The Central Mental Hospital, Dundrum, Dublin 14,

*Correspondence

\begin{abstract}
During the course of imprisonment, whether on remand or when serving a sentence, people sometimes need to be transferred to a psychiatric hospital. In Ireland the only psychiatric hospital a person can be transferred to is the Central Mental Hospital ( $\mathrm{CMH})$.

We describe 627 prison transfers to the CMH between 1983 and 1988. The number each year varied from 99 in 1983 to 127 in 1988 . The percentage on remand varied from $49 \%$ in 1984 to $31 \%$ in 1987 and 1986 . The average age of sentenced prisoners was 28 years and 35 years in the case of those on remand. The diagnostic categories were as follows: Schizophrenia (31\%), Reactive Depression $(23 \%)$, Personality Disorder (25\%), Mania (5\%), Drug and Alcohol (8\%) and Mental Handicap $(4 \%)$. The longest average stay in the hospital was seven weeks for Mania and the shortest was three weeks for Reactive Depression. The largest proportion on remand was for Mania (79\%) followed by Schizophrenia (58\%). We make recommendations about legislation and the role of the catchment area psychiatric hospital.
\end{abstract}

Key Words: Forensic Psychiatry, Prisons, Prison Transfers, Special Hospitals.

\section{Introduction}

During the course of imprisonment, whether on remand or serving a sentence, people sometimes need to be transferred to a psychiatric hospital. This can be because of a new mental disorder or a recurrence of an established one. In Ireland the Central Mental Hospital $(\mathrm{CMH})$ is the only psychiatric hospital to which an imprisoned person can be transferred. Transfers are covered by two types of Order. Hospital Orders (Criminal Justice Administration Act, 1914) are used as voluntary admission Orders. Ministerial Orders (Central Criminal Lunatic Asylum (Ireland) Act, 1845) need the signatures of two General Practitioners are are used as committal Orders (like a temporary certificate). In the former patients can go back to prison when they want to. In the latter Order the person can only return to the prison at the treating doctor's discretion. People on Ministerial Orders can also be treated against their will when necessary. For such people to be returned to prison they need to be "decertified" by two doctors signing a special form.

In the U.K. transfers can be to a special hospital, regional secure unit and local psychiatric hospital. The 1983 Mental Health Act covers these Orders (Section $47,48,35$ and 36). Literature on the topic of prison transfers is very sparse. Grounds ${ }^{1}$ gives a comprehensive account of prison transfers to Broadmoor Hospital between 1957 and 1983. The sample consisted of 380 cases of whom $72 \%$ had received determinate sentences and $28 \%$ life sentences. The period of the study was the time during which the 1957 Mental Health Act was being operated. He found that sex offenders stayed significantly longer than other categories of offender. He also found that patients admitted during the 1970's were more likely to be detained beyond the expiry date of their sentence than patients admitted during the 1960's. He gives various reasons for this and raises questions about legal safeguards for patients. This situation does not arise in Ireland as people who are transferred to the Central Mental Hospital during the course of a sentence must be released or transferred from the hospital at the expiry date of their sentence. Coid ${ }^{2,3}$ describes the difficulties involved in placing remand prisoners from Winchester Prison in hospital in the Oxford and Wessex regions between 1979 and 1983. He describes differences between the regions and the reluctance of some Consultants to accept mentally disordered patients. Robertson and Gibbens ${ }^{4}$ describe transfers of sentenced prisoners to local psychiatric hospitals between 1961 and 1977 under the 1959 Mental Health Act. They also describe the difficulty finding hospital places for such patients. The difficulties described by Coid and Robertson and Gibbens are not seen in Ireland as the only psychiatric hospital imprisoned people can be transferred to is the $\mathrm{CMH}$ and we can usually accept them on the same day that the request for transfer is made. Smith ${ }^{5}$ outlines the Psychiatric aspects of imprisonment in his book "Prison Health Care". He quotes many contributors to this debate and emphasises the problems of the psychotic patient, the mentally handicapped and the personality disordered. He describes the difficulties that the prison Medical Officer often has in placing people in catchment area hospitals and other facilities such as special hospitals and regional secure units. Arboleda-Florez and Chato ${ }^{6}$ describe prison transfers to a general hospital based forensic psychiatric unit in Calgary, Canada. They describe transfers to the unit from April 1978 to December 1982. They make recommendations about improving communication and sensitisation in staff at the hospital and prison. Weinstein ${ }^{7}$ gives us some information about the American experience of prison psychiatry. He outlines the position statement of the A.P.A. task force on psychiatric services in jails and prisons which is in favour of providing the same level of care for patients in prison as is available in the community. It is a call for the participation of Psychiatrists in "this important public service".

At the Central Mental Hospital the vast majority of our admissions are prison transfers. Our hospital has 
80 - 90 patients at any one time. Fifty per cent of the patient load is made up of prison transfers and the other $50 \%$ is made up of longer term prisoners such as the guilty but insane, unfit to plead, and those transferred from other hospitals (Section 207 of the 1945 Mental Treatment Act). We decided to analyse the characteristics of the prison transfers to understand better the psychiatric problems of people in prison and any changes that have taken place between 1983 and 1988. This study is confined to male patients. Approximately one in every six admission to the hospital is female and we report these in another study.

\section{Method}

We collected information concerning all male prison transfers for the years 1983 - 1988 inclusive from hospital registers and case notes. We are interested in age, the offence, whether on remand or serving a sentence (and if so how long), the length of stay in the hospital, the reason for admission, the final diagnosis and where the person was transferred to at the end of their stay. The ages of the remand and sentenced groups were compared using analysis of variance.

\section{Results}

\section{Ages and Numbers}

The total number of prison transfers over the six years was 627 . The sentenced prisoners numbered 387 with a mean age of 28 (S.D. $=8.66)$ and the remand prisoners numbered 240 with a mean age of 34 (S.D. $=12.14)$. This mean age was very constant in each year and the difference between the two groups was statistically significant: $\mathrm{F}(1,620)=61.01, \mathrm{P}<0.001$. The ages of five subjects were missing. Fig. 1 shows the numbers of sentenced and remand transfers to the hospital between the years 1983 - 1988. The numbers of those serving sentences out numbered the remand patients in all years, but were almost equal in the earlier years. Fig. 2 shows the number of remands, life sentences and other category of sentences. There are slight variations in the years, but in 1988 there seems to be an overall increase, especially in the number of remands (50) and in those serving short sentences (43).

FIGURE 1 - Number of prison transfers Total=627

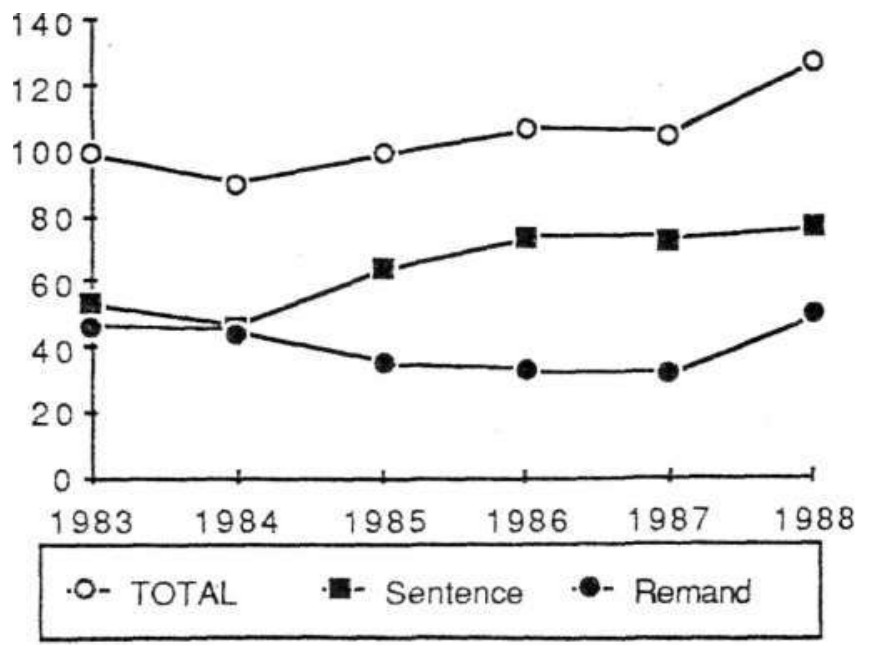

Figure 2 - Number on remand and sentenced

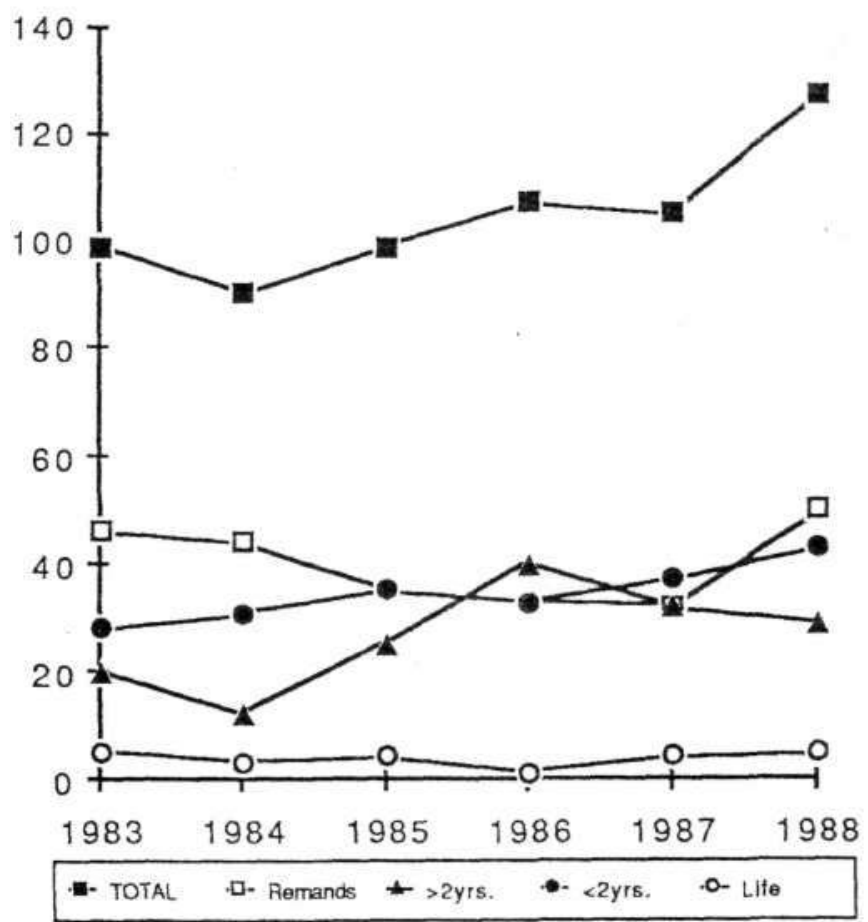

\section{Offences}

Table 1 shows the number of patients in the various categories of offences. There is little variation in the numbers over the years, but there is a sustained increase in the last category referred to as "other" and this is made up of offences such as drugs related offences, public order offences and firearms.

It is interesting that murder, offences against the person and sex offences seem to be relatively stable as regards the numbers admitted to the $\mathrm{CMH}$.

TABLE 1 - Categories of offences

\begin{tabular}{lccccc}
\hline $\begin{array}{l}\text { Offence } \\
\text { Type }\end{array}$ & Murder & $\begin{array}{c}\text { Against } \\
\text { the Person }\end{array}$ & Sex & Property & Other \\
\hline $\begin{array}{l}\text { Admission } \\
\begin{array}{l}\text { Numbers } \\
1983-88\end{array}\end{array}$ & $22(25)$ & $74(63)$ & $48(27)$ & $193(69)$ & $51(55)$ \\
\end{tabular}

Numbers in brackets are remand prisoners, the others are sentenced.

\section{Diagnostic Categories}

Table 2 summarises information about offence type and diagnostic category. Depression and stress disorders were dealt with together. In each year there was no average only one of two cases of endogenous depression.

All of the other depressive disorders were situational or reactive depression. The vast majority of the personality disorders were anti social personality disorder. In this group there is quite a number in the longer term sentences especially life imprisonment. Eleven of the 61 prisoners in this category serving sentences longer than two years were serving life sentences. 
TABLE 2 - Summary of 1983-1988 admissions by diagnostic calegory and offence type

\begin{tabular}{|c|c|c|c|c|c|c|c|c|}
\hline & Murder & 10 & 1 & 8 & 15 & 6 & 1 & 6 \\
\hline Offence & O.A.P. & 64 & 7 & 20 & 26 & 4 & 9 & 7 \\
\hline \multirow[t]{3}{*}{ Type } & Sex & 7 & 2 & 20 & 31 & 5 & 4 & 6 \\
\hline & Other & 111 & 19 & 97 & 86 & 8 & 37 & 10 \\
\hline & & Schi & Mania & $\begin{array}{l}\text { Dep \& } \\
\text { Stress }\end{array}$ & & & $\begin{array}{l}\text { Drugs/ } \\
\text { Alcohol }\end{array}$ & Other \\
\hline
\end{tabular}

Table 3 summarises information about diagnostic categories. average stay and the percentage on remand. The largest diagnostic category is schizophrenia (31\%) followed by personality disorder (25\%) and depression/ stress $(23 \%)$. The vast majority of the manic patients (79\%) were on remand during their time at the Central Mental Hospital and a high proportion of the schizophrenic patients $(58 \%)$.

TABLE 3 - Summary of 1983-1988 admissions by diagnostic calegory

Number (\% total) Mean length of stay \% on Remand

\begin{tabular}{lrccc} 
Schizophrenia & 192 & $(31 \%)$ & 5 weeks & $58 \%$ \\
Mania & 29 & $(5 \%)$ & 7 weeks & $79 \%$ \\
$\begin{array}{l}\text { Depression/ } \\
\text { Stress }\end{array}$ & $145(23 \%)$ & 3 weeks & $18 \%$ \\
P.D. & $159(25 \%)$ & 5 weeks & $19 \%$ \\
M.H. & $24(4 \%)$ & 6 weeks & $38 \%$ \\
Drugs \% Alcohol & $51(8 \%)$ & 4 weeks & $39 \%$ \\
Other & $27(4 \%)$ & (large variation) & $50 \%$ \\
& $627(100 \%)$ & & \\
\cline { 2 - 2 } & \multicolumn{2}{c}{6} & & \\
\hline
\end{tabular}

P.D. = Personality Disorder, M.H. = Mental Handicap,

\section{Committal Orders}

These are all dealt with by Ministerial Orders (see introduction). In 1988 10\% (13 cases) of the admissions were by Ministerial Order. There were seven suffering from schizophrenia, one from mania, two from organic brain syndromes and three with personality disorders. In 1987 there were nine cases (9\%), in 1986 one case, in 1985 no cases, in 1984 two cases and in 1983 four cases.

\section{Discharges}

All of the discharges from the hospital were back to the prison of origin except for those transferred back to their catchment area hospital or the tiny number who are discharged directly into the community. Over the study period 85 patients were transferred to their local catchment area hospital and this represents $14 \%$ of the total 627 . This was a relatively stable proportion over the years. Seventy of these transfers were prisoners on remand and this represents $82 \%$ of those transferred to their local hospitals. In those cases the charges were minor and were withdrawn (nolle prosequi) with the consent of the gardai and the Director of Public Prosecutions. This process is only operated $w^{?}$ hen the person is mentally disturbed and the local psychiatric hospital agrees to admit the patient. The remaining transfers were of prisoners who were at the end of their sentences but who still needed a period of hospitalisation.

\section{Discussion}

The information presented about the sample of patients between 1983 and 1988 ar the Central Mental Hospital produces very few surprises. The relatively large number of non serious offences is explained by the fact that the $\mathrm{CMH}$ acts as a special hospital, regional secure unit and local psychiatric hospital in some cases. Again it is surprising that schizophrenics usually only spend on average five weeks with us because a large proportion of those $(58 \%)$ were on remand. The courts put us under pressure to find a psychiatric placement for them because most courts are reluctant to sentence obviously mentally ill people to prison when the charges are minor. The Gardai and also the Director of Public Prosecutions have the same view. Of interest is the small number of manics $(5 \%)$ the majority of whom were on remand at the lime of coming to the Central Mental Hospital. They on average spent seven weeks with us and were nearly all placed in their local psychiatric hospital. We certainly see a smaller number of endogenously depressed patients than manics. Could it be that the manic patient is more likely to find his way into prison and consequently to the $\mathrm{CMH}$ than is the depressed patient? Major depression is quite rare among the prison population in our experience. Minor reactive depressions and stress related disorders are much more common. Only $4 \%$ of our sample of 627 were described as suffering from mental handicap. A large number had other categories of psychiatric disorder and their low intelligence was the least important. Smith describes studies which estimate that between $45 \%$ and $14 \%$ of the prison population are sub-normal

Ministerial Orders were used relatively frequently in 1988 and 1987 for the transfer of patients to the Central Mental Hospital from prison. This seems to be a recent phenomenon as these Orders were hardly used in the earlier years of the study. One wonders if this represents a change in approach by the prison Medical Officers in Ireland or are more of the transfers reluctant to co-operate with the doctors advice. We feel that a review of the legislation that covers prison transfers in the Republic would be useful. The two Acts that we operate under date from 1914 and 1845. The CMH doctors sometimes are unclear about their legal position with regard to these two Orders and also the issue of the patients' rights in uncertain.

Many of those admitted to the CMH have committed only minor offences. The Central Mental Hospital is a security hospital and is really designed for the serious and dangerous offender. It would seen reasonable that local catchment area hospitals could be involved earlier in the assessment process of those prisoners who need assessment on remand. Local courts could liaise directly with local hospitals for this purpose. Prisoners who need psychiatric treatment who have committed only minor offences should be treated in their local psychiatric hospitals rather than in a security hospital. New legislation would be required to implement these recommendations.

Acknowledgements

We would like to thank Patricia Walsh for secretarial assistance and Ivor Shorts, Psychologist, for help with statistics.

References

1. Grounds A. The transfer of sentenced prisoners to hospital, 1960 - 1983 A study in one Special Hospital. Br J Criminology 1990 (in press).

2. Coid J. Mental!v abnormal prisoners on remand (i). Br Med J 1988; 296 : 1779-82.

3. Coid J. Mentallv abnormal prisoners on remand (ii), Br Med J 1988; 296: 1783-4.

4. Robertson G, Gibbens TCN. Transfers from prisons to local psychiatric hospitals under Section 72 of the 1959 Mental Health Act. Br Med J 1980; 280: 1263-66.

5. Smith R. Prison Health Care. London: British Medical Association. 19S9.

6. Arboleda - Florez J, Chato F. Issues regarding admissions from a correctional facility to a hospital forensic unit. Ini J Offender Therapy and Comparative Criminology 1985: 29: 43-62.

7. Weinstein H. Psychiatric services in jails and prisons: who cares? Am J Psychiatry 1989; 146: 1094-95. 